\title{
GAIA Insufficient Evidence for Diagnosis of Fetal Growth Restriction
}

National Cancer Institute

\section{Source}

National Cancer Institute. GAIA Insufficient Evidence for Diagnosis of Fetal Growth

Restriction. NCl Thesaurus. Code C128915.

GAIA Insufficient Evidence for Diagnosis of Fetal Growth Restriction is defined as the absence of an ultrasound for use in the assessment of estimated fetal weight. 